American Journal of Agricultural and Biological Sciences 3 (3): 602-609, 2008

ISSN 1557-4989

(C) 2008 Science Publications

\title{
Irrigated and Non-Irrigated Wheat Classification Based on Cultivation Calendar by IHS Algorithm
}

\author{
${ }^{1}$ Ashourloo Davood, ${ }^{1}$ Matkan Ali Akbar, ${ }^{2}$ Aghighi Hossain \\ ${ }^{1}$ Hosseni Amin,${ }^{3}$ Gholampour Ali and ${ }^{3}$ Ashourloo Morteza \\ ${ }^{1}$ Department of Remote Sensing and GIS,Faculty of Earth Science, Shahid Beheshti University,G,C \\ ${ }^{2}$ Iranian Space Agency \\ ${ }^{3}$ Master science of Remote Sensing, Shahid Beheshti University, Tehran, Iran
}

\begin{abstract}
In order to extract the wheat the bi-temporal Spot images were ordered based on cultivation calendar of wheat and other crops. As the crops reflection properties showed many variations, for precise classification many signatures are needed. Appropriate bands for classification were selected by divergence algorithm. These bands converted to IHS and for recognizing the reflection changes in the cultivated areas, appropriate parameters for Hue and Saturation were used and all of the wheat cultivated areas were classified. The result of hue was used as input for extracting Irrigated and nonirrigated wheat by saturation. The results showed that in limited signatures and bands, IHS method acts more efficiently than other classification methods such as maximum likelihood and spectral angel mapper.
\end{abstract}

Key words: Wheat, cultivation calendar, classification, signatures, HIS

\section{INTRODUCTION}

Information on the cultivated areas of agricultural products is as basic tools in preparing import-export policies, pricing agricultural products, planning agricultural developments and other relevant issues. In comparison to other traditional methods, nowadays, it is possible to have statistics on the cultivated areas with different products, by spending less time and expense thanks to satellite images. Due to alternation images, wide area which is covered by the image, acquisition in different wave lengths and finally due to quick and computerized data analysis, the remote sensing data are applied in the analyses related to crops, so that literature represent many researches on recognizing and separating of grain-plants through multi temporal images. Thompson ${ }^{[2]}$ through Lacie model and linear relation between the spectral reflections of agricultural products in the growth season could determine wheat yield by MSS data in Texas. Combining this model with accurate agronomic-meteorological data, acceptable results may be achieved. But the point is that, since accurate agronomic-meteorological data is not available in Iran. Dusek et al. ${ }^{[5]}$ studied the spectral reflection of wheat in the growth season and considered every condition such as irrigation, growth situation and soil humidity and attained the wheat index using radiometer, but it was not applicable in satellite images.
Labus et al ${ }^{[9]}$ studied wheat growth profile by NDVI of AVHRR data in local and regional scale. The results showed that there are a strong correlation between the wheat production and NDVI. Hoekman and Vissers ${ }^{[21]}$ used RADAR data by polarmetric algorithm in Canada and classified different agricultural products like wheat, with the accuracy of about $96 \%$. The efficiency of maximum likelihood and artificial neural network-were considered by Murthy and colleagues with using multitemporal images and consequently wheat cultivated areas were extracted more accurately by artificial neural network algorithm Murthy et al. ${ }^{[11]}$. Accordingly .The main purpose of the present study, in addition to determining the appropriate time of acquisition images, was to classify irrigated and dry wheat cultivated areas.

\section{MATERIALS AND METHODS}

Study area: In the present research, the study areas are Hamedan and Bahar with the area of $5452 \mathrm{~km}^{2}$ in North West of Iran. Figure 1 shows the location of the study. Its elevation is almost $1800 \mathrm{~m}$ and the average annual rainfall is $350 \mathrm{~m}$. According to Domarton classification $^{[1]}$, its climate is cold and dry. Nonirrigated Wheat cultivation in these areas mostly occurs in autumn season and irrigated Wheat cultivation in some regions occurs in spring ${ }^{[7]}$.

Corresponding Author: Davood Ashourloo, Department of Remote sensing, Shahid Beheshti University, Tehran, Iran Tel: +98-299030778 Fax: +98-22431788 


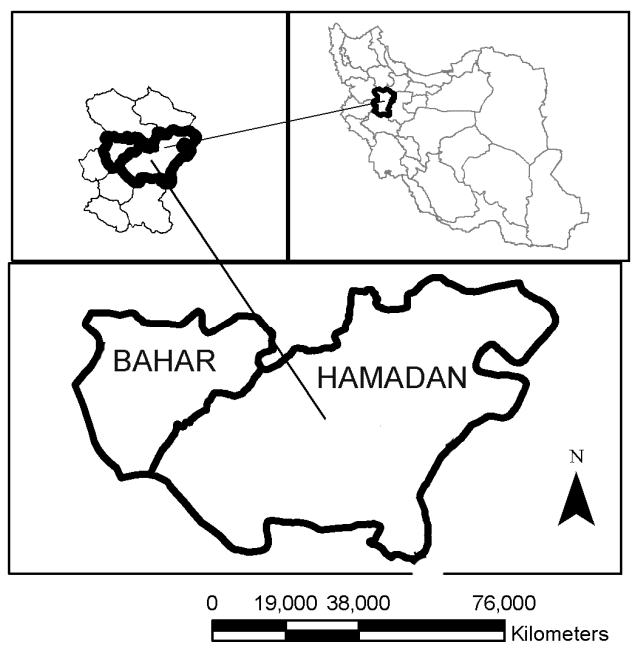

Fig. 1: Location of study area for extracting wheat under cultivation

It was necessary to have a comparative study about growth condition of other major products-rather than wheat-of the area based on cultivating calendar, so that the appropriate time of satellite imaging were determined.

Hence, in order to determine time range to prepare satellite images, first, the cultivating calendar of different products were taken from the JihadAgricultural Organization of Hamedan. Then, based on the obtained data the time of cultivation, peak of greenness, harvested and ploughing of different products were studied in comparison to wheat and the appropriate time of acquisition data and sampling were determined.

\section{Cultivation calendar of crops}

Grain plants: Physiologically, Barely is similar to wheat, therefore, it is difficult to distinguish these two plants through satellite data. In the study area, harvest of barely is started 15-20 days earlier than wheat. Meanwhile, the first 10 days of May is the time when wheat is on the peak of greenness, barely had passed this peak ${ }^{[14]}$. On the other hand, the last days of July is the time when barely has been harvested but not wheat.

It is to be mention that, in this region, when the wheat is yellow, corn is on peak of greenness ${ }^{[12]}$. Therefore, it can be separated easily in satellite images.

Cereal plants: The growth of stem and leaves are small $^{[10]}$. In this farms soil reflection is more than plant reflection. Hence, during the first 10 days of May wheat is exactly green at this time. The harvesting time of pea and wheat is the same, with this difference that since pea is collected from its root after harvest it seems as if the farm has been ploughed. Other plants of cereal group are like pea.

Summer vegetation and industrial vegetation: Cultivation of this group of plants occurs at the beginning of spring. In terms of reflection, during the first 10 days of May, soil reflection is predominant because these plants are passing the first stages of growth. Therefore, they do not seem to be homogeneous green, like wheat. On the other hand, since growth time is long, they look green at the end of July ${ }^{[13]}$, while wheat is not green and is ready to be harvested.

Forage plants: Forage plants like alfalfa are annual and perennial. They are cultivated from the beginning up to the end of April and the harvest can be started that year too. The beginning stages of growth for alfalfa take place slowly and lasts about one or two months ${ }^{[3]}$. Therefore, if they are cultivated in present year, soil reflection will be predominant. If so, at the end of July, they would have passed growing stage and will look green. But if they were planted in the last years, they could be harvested within several stages and as winter is over, they look quite green in the spring. Studying cultivating calendar of other products of this group like clover and sainfoin shows that there is no problem in their separation with wheat. At the end of July, forage plants lie in peak of greenness, while wheat has passed it.

Trees and shrubs: At the first 10 days of May and at the end of July, they look green, while the greenness of wheat is over at the end of July which is clearly recognizable from trees ${ }^{[18]}$.

\section{Data set}

Spot data: The results of survey on the cultivating calendar of different products in the study area showed that in order to estimate cultivated areas of the wheat, it is necessary to take SPOT images in two periods: first, the peak of greenness in wheat farms, second, the harvested time of wheat farms. Table 1 and 2 respectively, show bands characteristics of SPOT5 bands in visible and near infrared area of electromagnetic spectrum ${ }^{[6]}$ and compare of the reflections of different agricultural products to determine appropriate time for preparing images in both times. Accordingly, SPOT images were ordered.

Ground truth data: In order to classification and accuracy assessment of wheat farms the totally 337 
Am. J. Agri. \& Biol. Sci., 3 (3): 602-609, 2008

Table 1: Identify of spot satellite bands

\begin{tabular}{llll}
\hline Band & Spectral rang & Resolution & Wave length \\
\hline 1 & Visible & 10 meter & $0.49-0.60 \mu \mathrm{m}$ \\
2 & Visible & 10 meter & $0.60-0.68 \mu \mathrm{m}$ \\
3 & Near infrared & 10 meter & $0.78-0.89 \mu \mathrm{m}$ \\
4 & Middle infrared & 20 meter & $1.58-1.75 \mu \mathrm{m}$ \\
\hline
\end{tabular}

Table 2: Comparison of different agriculture crops cultivation calendar versus the wheat

\begin{tabular}{lll}
\hline $\begin{array}{l}\text { Condition of growing } \\
\text { in second acquire }\end{array}$ & $\begin{array}{l}\text { Condition of growing } \\
\text { in first acquire }\end{array}$ & $\begin{array}{l}\text { Kind } \\
\text { of crops }\end{array}$ \\
\hline $\begin{array}{l}\text { Harvested } \\
\text { Pick of greenness }\end{array}$ & $\begin{array}{l}\text { Pick of greenness } \\
\text { Beginning of growing stage and } \\
\text { soil reflection is predominant } \\
\text { Maximum of greenness but soil } \\
\text { reflection is predominant }\end{array}$ & $\begin{array}{l}\text { Wheat } \\
\text { Summer } \\
\text { crops } \\
\text { Cereal }\end{array}$ \\
Peginning of growing stage and & $\begin{array}{l}\text { Industrial } \\
\text { coil reflection is predominant }\end{array}$ \\
Pick of greenness & $\begin{array}{l}\text { Beginning of growing stage soil } \\
\text { reflection is predominant } \\
\text { forage }\end{array}$ \\
$\begin{array}{l}\text { plants } \\
\text { Pick of greenness }\end{array}$ & Maximum of greenness & $\begin{array}{l}\text { Perennial } \\
\text { forage }\end{array}$ \\
plants & Maximum of greenness & Threes \\
Pick of greenness & &
\end{tabular}

Table 3: Sampling points and aim of sampling

\begin{tabular}{lll}
\hline Stage & Number of samples & Aim of sampling \\
\hline First & 68 & farm recognition and signature \\
Second & 215 & Signature \\
Third & 54 & test sampling \\
\hline
\end{tabular}

samples were collected. Table 3 shows the details of samplings.

The obtained information included GPS accuracy, neighbor farms. In order to decrease the effect of exceptional pixels, these data were applied in confidence level of $95 \%$ and according to Eq. 1 (Sepehdost, 2003).

$$
\begin{aligned}
& \mathrm{P}\left(\frac{|\overline{\mathrm{x}}-\mu|}{\frac{\delta}{\sqrt{\mathrm{n}}}}<\mathrm{Z}_{1-\frac{\alpha}{2}}\right)=\frac{1-\alpha}{100} \Rightarrow \mu \\
& -\frac{\delta}{\sqrt{\mathrm{n}}} \mathrm{Z}_{1-\frac{\alpha}{2}}<\overline{\mathrm{X}}<\mu+\frac{\delta}{\sqrt{\mathrm{n}}} \mathrm{Z}_{1-\frac{\alpha}{2}} \\
& \stackrel{1-\alpha=\frac{95}{100} \Rightarrow \alpha-0.05 \Rightarrow \mathrm{Z}_{1-\frac{\alpha}{2}}=\mathrm{Z}_{0.975=1.96}}{\longrightarrow} \mu-1.96 \frac{\delta}{\sqrt{\mathrm{n}}}<\overline{\mathrm{X}}<\mu+1.96 \mathrm{X} \frac{\delta}{\sqrt{\mathrm{n}}} \\
& \mathrm{P}=\text { Probability } \\
& \mathrm{X}=\text { Mean of sample } \\
& \mu=\text { Mean of society } \\
& \alpha=\text { Significant } \\
& \mathrm{Z}=\text { Standard normal variable } \\
& \mathrm{n}=\text { Number of sample }
\end{aligned}
$$

Table 4: The mean of DN in study area for crops

\begin{tabular}{llllllll}
\hline \multicolumn{3}{c}{ Non- } & & & & & \\
Irrigated & irrigated & & $\begin{array}{l}\text { Dry } \\
\text { green }\end{array}$ & $\begin{array}{l}\text { Ever } \\
\text { crops }\end{array}$ & Industrial \\
Band wheat wheat & Pillow & land & \\
\hline Red (t2*) & 150 & 144 & 142 & 102 & 53 & 67 & \\
Nir (t2) & 153 & 135 & 121 & 99 & 218 & 183 & \\
Green (t2) & 152 & 139 & 143 & 119 & 85 & 91 & \\
Red (t1**) & 65 & 114 & 154 & 101 & 79 & 151 & \\
Nir (t1) & 126 & 128 & 105 & 80 & 128 & 116 & \\
Green (t1) & 69 & 96 & 117 & 94 & 78 & 115 & \\
\hline
\end{tabular}

**t1: First acquire *t2: Second acquire

Choosing appropriate bands for classification: Since, the images have been taken in two different periods in order to separate the wheat cultivated areas; three bands related to each time were inserted into each file.

In order to decrease data dimension and also to prevent the bands with less effect in wheat separation process, the sample farms were transferred on to images and their average reflection was extracted the results have been shown in Table 4.

Separability analysis was applied on these tables by introducing the two classes; wheat and non-wheat through Eq. $1^{[20]}$.

$$
\begin{aligned}
& 1 /\left(2 \operatorname{tr}\left(\left(c_{\mathrm{i}}-c_{\mathrm{j}}\right)\left(\mathrm{c}_{\mathrm{i}}^{-1}-\mathrm{c}_{\mathrm{j}}^{-1}\right)\right)\right) \\
& +1 /\left(2 \operatorname{tr}\left(\left(\mathrm{c}_{\mathrm{i}}^{-1}-\mathrm{c}_{\mathrm{j}}^{-1}\right)\left(\mu_{\mathrm{i}}-\mu_{\mathrm{j}}\right)\left(\mu_{\mathrm{i}}-\mu_{\mathrm{j}}\right)^{\mathrm{T}}\right)\right) \\
& \operatorname{TD}_{\mathrm{ij}}=2000\left(1-\exp \left(\mathrm{D}_{\mathrm{ij}} / 8\right)\right)
\end{aligned}
$$

$\mathrm{i}, \mathrm{j}=$ The tow signatures classes being

$c_{i}=$ The covariance matrix of signature $i$

$\mathrm{c}_{\mathrm{j}}=$ The covariance matrix of signature $\mathrm{j}$

$\operatorname{tr}=$ The trace function (matrix algebra)

$\mathrm{T}=$ The transposition function

Accordingly, transformed divergence was used as separability index ${ }^{[8]}$. The value range of this index changes between $0-20$. So that, if the result is more than 1.9 the classes will be separable, between 1.7-1.9, the separability is fairly good and less than 1.7 is considered as weak ${ }^{[16]}$. The results of separability analysis are shown in Table 5.

Training site selection: Selecting of the training site for IHS, ML and SAM algorithms was done increasingly:

It started with $20 \%$ of the samples and it increased with the rate of $10 \%$ up to $70 \%$.

Classification based on HIS system: In order to classify the wheat cultivation areas, the transforming of RGB in to IHS was carried out in appropriate bands for 
Table 5: The divergence results of wheat versus other crops in different bands

\begin{tabular}{llllll}
\hline $\mathrm{N}$ & Band & divergence & $\mathrm{N}$ & Band & Divergence \\
\hline 1 & $1 \mathrm{a}, 2 \mathrm{~b}, 3 \mathrm{c}, 4 \mathrm{~d}, 5 \mathrm{e}$, 6f & 1.91 & 5 & $1,2,4,5,6$ & 1.9 \\
2 & $2,4,5$ & 1.9 & 6 & $1,2,3,4,5$ & 1.88 \\
3 & $1,2,4,5,6$ & 1.9 & 7 & $2,3,5,6$ & 1.87 \\
4 & $1,2,4,6$ & 1.89 & 8 & $1,2,3,4,6$ & 1.89 \\
\hline
\end{tabular}

a: Green of first acquire; b: Red of first acquire; c: Near infrared of first acquire; d: Green of first acquire; e: Red of second acquire; f::

Near infrared of second acquire

separation of the wheat cultivated areas (containing Red of second acquisition, Near Infrared of second acquisition and Red of first acquisition that they have high separility according to Table 5) therefore after normalization of the RGB data through Eq. 3, the Eq. 47 were applied to transforming RGB to HIS ${ }^{[4]}$.

$$
\begin{aligned}
& r=R /(R+G+B), g=G /(R+G+B), \\
& b=B /(R+G+B)
\end{aligned}
$$

Than hue computed wit 5 and 6 equitation

$$
\begin{aligned}
& \text { hue }=\cos ^{-1}\left[\frac{0.5[(\mathrm{r}-\mathrm{g})+(\mathrm{r}-\mathrm{b})]}{\left[(\mathrm{r}-\mathrm{g})^{2}+(\mathrm{r}-\mathrm{b})(\mathrm{g}-\mathrm{b})\right]^{\frac{1}{2}}}\right] \mathrm{h} \in[\circ, \pi] \text { for } \mathrm{g} \leq \mathrm{b} \\
& \text { hue }=2 \pi-\cos ^{-1}\left[\frac{0.5[(\mathrm{r}-\mathrm{g})+(\mathrm{r}-\mathrm{b})]}{\left[(\mathrm{r}-\mathrm{g})^{2}+(\mathrm{r}-\mathrm{b})(\mathrm{g}-\mathrm{b})\right]^{\frac{1}{2}}}\right]
\end{aligned}
$$

Saturation and Intensity is computed by using of 6 and 7 equations respectively

$$
\begin{aligned}
& \text { Saturation }=1-3 \cdot \min (\mathrm{r}, \mathrm{g}, \mathrm{b}) \\
& \text { int ensity }=(\mathrm{R}+\mathrm{B}+\mathrm{B}) / 3.255
\end{aligned}
$$

After transforming RGB into HIS, the 50\% training sites were used on Hue, Saturation and Intensity components that the results for different farms are shown in table 6. Once more, transform divergence was carried out by Eq. 1 and the results were studied separately for Hue, saturation and intensity in the irrigated and non-irrigated farms to determine appropriate quantity for the separation of wheat farms from non-wheat farms.

Classification with SAM and ML algorithms: In order to compare the accuracy of IHS classification with other methods, SAM from the spectral methods
Table 6: The mean of digital number in IHS system in study area for crops

\begin{tabular}{lllllll}
\hline & $\begin{array}{l}\text { Irrigated } \\
\text { wheat }\end{array}$ & $\begin{array}{l}\text { Non- } \\
\text { irrigated } \\
\text { wheat }\end{array}$ & Pillow & $\begin{array}{l}\text { Dry } \\
\text { land }\end{array}$ & $\begin{array}{l}\text { Ever } \\
\text { green }\end{array}$ & $\begin{array}{l}\text { Industrial } \\
\text { crops }\end{array}$ \\
\hline Hue & 62 & 42 & 278 & 320 & 129 & 163 \\
Saturation & 58 & 21 & 22 & 3 & 76 & 63 \\
Intensity & 60 & 56 & 63 & 40 & 85 & 72 \\
\hline
\end{tabular}

and ML as one of the most important statistical classification methods, were selected. Six bands were used for SAM and ML classification.

SAM classification: In SAM classification, as one of the supervise classification method; the similarity between two spectra is determined through computing the spectral angle between them. This method is discussed in a multi-dimensional space, where, the dimensions of this space are equal to the number of bands and Eq. 8 is used for This purpose $\mathrm{e}^{[15]}$.

$$
\theta=\cos ^{-1}\left[\frac{\sum_{\mathrm{i}=1}^{\mathrm{n}} \mathrm{t}_{\mathrm{i}} \mathrm{r}_{\mathrm{i}}}{\sqrt{\sum_{\mathrm{i}=1}^{\mathrm{n}} \mathrm{t}_{\mathrm{i}}^{2} \sum_{\mathrm{i}=1}^{\mathrm{n}} \mathrm{r}_{\mathrm{i}}^{2}}}\right]
$$

$\theta=$ Calculated angel

$\mathrm{t}_{\mathrm{i}}=$ Angel of class

$\mathrm{r}_{\mathrm{i}}=$ Angel of unknown pixel

$\mathrm{n}_{\mathrm{i}}=$ Number of band

Accordingly to this equation, in spectral space, each pixel is shown with a point. Also each point is considered as basis and its distance with other points is computed based on the angle.

Generally, when different pixels are available with a similar angle these pixels belong to one class.

ML classification: Maximum likelihood classification assumes that the statistics for each class in each band are normally distributed and calculates the probability that a given pixel belongs to a specific class. Each pixel is assigned to the class that has the highest probability. To this purpose, the belonging probability of each pixel to a certain class is computed through Eq. $9^{[16]}$.

$$
\mathrm{g}_{\mathrm{i}}(\mathrm{x})=\ln \mathrm{P}\left(\mathrm{w}_{\mathrm{i}}\right)-\frac{1}{2} \ln \left|\Sigma_{\mathrm{i}}\right|-\frac{1}{2}\left(\mathrm{x}-\mathrm{m}_{\mathrm{i}}\right) \mathrm{t} \sum \mathrm{i}-1\left(\mathrm{x}-\mathrm{m}_{\mathrm{i}}\right)
$$

Where:

$$
\begin{aligned}
\mathrm{i}= & \text { Class } \\
\mathrm{x}= & \mathrm{N} \text {-dimensional data (where } \mathrm{n} \text { is the number of } \\
& \text { bands) }
\end{aligned}
$$


$\mathrm{P}\left(\mathrm{w}_{\mathrm{i}}\right)=$ Probability that class $\mathrm{w}_{\mathrm{i}}$ occurs in the image and is assumed the same for all lasses

$\left|\Sigma_{\mathrm{i}}\right|=$ Determinant of the covariance matrix of the data in class $\mathrm{w}_{\mathrm{i}}$

$\sum \mathrm{i}-1=$ Its inverse matrix

$\mathrm{m}_{\mathrm{i}} \quad=$ Mean vector

\section{RESULTS AND DISCUSSION}

Hue was used as component for wheat extraction, because in this band separability average is 1.97 for irrigated farms and 1.96 for non-irrigated areas which shows more separability rather than intensity and saturation. In the classification based on these results of transform divergence of different bands are shown in Table 7-9 for hue, Saturation and Intensity, respectively.

At first, in order to extract the wheat cultivated areas, hue data were used in $95 \%$ confidence level. Table 10 shows the mean variability and standard deviation of hue and saturation for the irrigated and non-irrigated wheat.

For wheat extraction, hue is 28-68. When the saturation comes closer to zero, it means the data could be considered equal for $\mathrm{RGB}^{[4]}$. Minimum of the saturation is necessary because lack of it causes that every class with saturation comes closer to zero to be put into wheat class. Thus, it was necessary to apply saturation range more than zero as according to Eq. 10 .

Wheat $=(67>$ hue $>28$ and saturation $>0)$

According to the results of Table 10, saturation range for the irrigated farms was selected 50-64 and for non-irrigated 13-30.

Equations 11, 12 were used for extracting the nonirrigated wheat and irrigated wheat, respectively over the result of 10 equations.

$$
\begin{aligned}
& \text { Non-Irrigated Wheat }=13>\text { Saturation }>30 \\
& \text { Irrigated Wheat }=64>\text { Saturation } 50 \text { ) }
\end{aligned}
$$

Also Fig. 2 presents the results of the classification accuracy for SAM, ML and IHS algorithms. At the first stage of selecting, HIS is more accurate than ML, SAM that they use 6 bands for classification. As the training site increases from $20-70 \%$, the total accuracy in all algorithms increases and the accuracy of ML equals to IHS.

As Fig. 2 shows, as the sample size increases, accuracy ML also increases due to approaching to normal distribution. But when the samples are limited
Table 7: The divergence results of irrigated and non-irrigated wheat in agriculture lands for Hue

\begin{tabular}{llllll}
\hline & Pillow & $\begin{array}{l}\text { Dry } \\
\text { land }\end{array}$ & $\begin{array}{l}\text { Ever } \\
\text { green }\end{array}$ & $\begin{array}{l}\text { Industrial } \\
\text { crops }\end{array}$ & Mean \\
\hline Irrigated wheat & 2 & 1.96 & 1.97 & 2 & 1.97 \\
Non-irrigated wheat & 1.94 & 1.94 & 2 & 1.97 & 1.96 \\
\hline
\end{tabular}

Table 8: The divergence results of irrigated and non-irrigated wheat in agriculture lands for saturation

\begin{tabular}{llllll}
\hline & Pillow & $\begin{array}{l}\text { Dry } \\
\text { land }\end{array}$ & $\begin{array}{l}\text { Ever } \\
\text { green }\end{array}$ & $\begin{array}{l}\text { Industrial } \\
\text { crops }\end{array}$ & Mean \\
\hline Irrigated wheat & 1.92 & 1.93 & 1.86 & 1.73 & 1.6 \\
Non-irrigated wheat & 1.76 & 1.91 & 1.97 & 1.96 & 1.9 \\
\hline
\end{tabular}

Table 9: The divergence results of irrigated and non-irrigated wheat in agriculture lands for intensity

\begin{tabular}{llllll}
\hline & Pillow & $\begin{array}{l}\text { Dry } \\
\text { land }\end{array}$ & $\begin{array}{l}\text { Ever } \\
\text { green }\end{array}$ & $\begin{array}{l}\text { Industrial } \\
\text { crops }\end{array}$ & Mean \\
\hline Irrigated wheat & 1.4 & 1.71 & 1.94 & 1.9 & 1.73 \\
Non-irrigated wheat & 1.21 & 1.66 & 1.93 & 1.87 & 1.66 \\
\hline
\end{tabular}

Table 10: Quantity of hue and saturation variations in irrigated and non-irrigated wheat

\begin{tabular}{lllll}
\hline Kind of crops & Max & Max & SD & Mean \\
\hline Non-irrigated wheat-hue & 32 & 54 & 6.3 & 40 \\
Irrigated wheat-hue & 49 & 68 & 5.1 & 57 \\
Non-irrigated wheat-saturation & 15 & 32 & 4.5 & 21 \\
Irrigated wheat-saturation & 43 & 62 & 4 & 58 \\
\hline
\end{tabular}



Fig. 2: Relation between accuracy and used sample for classification

IHS will be more accurate. It can be concluded that a methods which gives better results with limited samples, has importance.

In the extracting the wheat cultivated areas, it was observed that with same cultivating calendar in the two wheat farms, one species of wheat has some differences in reflection and in second series of images these differences are more obvious that have been shown in Table 11.

As it can be observed, reflection in different irrigated or non-irrigated cultivated areas is also 
Am. J. Agri. \& Biol. Sci., 3 (3): 602-609, 2008

\begin{tabular}{|c|c|c|c|c|c|c|c|}
\hline $\mathrm{N}$ & varieties of wheat & Red t2 & Nir t2 & Red t1 & Hue & Saturation & Identity \\
\hline $\bar{a}$ & Omid-irrigated wheat(1) & 163 & 158 & 89 & 56 & 45 & 64 \\
\hline $\mathrm{b}$ & Omid-irrigated wheat(2) & 160 & 155 & 91 & 56 & 43 & 63 \\
\hline c & Alvand-irrigated wheat & 151 & 146 & 88 & 55 & 42 & 59 \\
\hline $\mathrm{d}$ & Azar-non-irrigated wheat & 142 & 127 & 107 & 51 & 25 & 56 \\
\hline $\mathrm{e}$ & Sardar-non-irrigated wheat & 141 & 129 & 126 & 52 & 11 & 55 \\
\hline $\mathrm{f}$ & Omid-irrigated wheat (3) & 122 & 128 & 89 & 55 & 75 & 51 \\
\hline
\end{tabular}

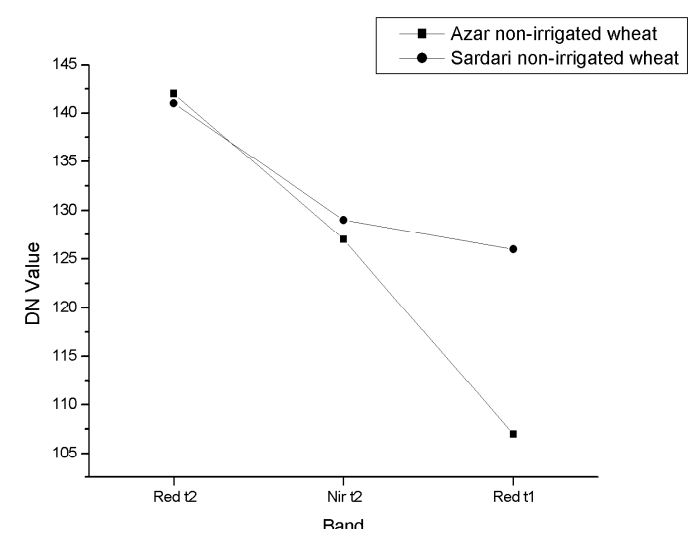

Fig. 3: Reflectance graph between varieties of irrigated wheat

different i.e., a with $\mathrm{b}$ in Table 11 and Fig. 3. Also the reflection intensity in different areas is different i.e., a with $\mathrm{c}$ in Table 11 and Fig. 3. These reflection changes in wheat cultivated areas make it difficult to recognize and classify the farms with used of remote sensing techniques. The major problem in extracting the wheat cultivated areas is the difference between the reflections of the second stage data, which in spite of all similar growth situations in one specie, are different i.e., a with f samples in Table 11 and Fig. 3, but at the first stage data, the reflection is the same. Our finding showed that the major reason of the difference in lands reflection is non-simultaneous harvest of wheat due to lack or limited access to harvesting machines. This difference increases with animal grazing and wind which mostly blows in summer in this region. The reflection changes increases in the wheat farms.

In order to increase accuracy in classification, it is necessary to increase the training samples and to select the data with perfect accuracy for classification which, it leads to spending more time and expense i.e., classification accuracy of ML and SAM in Fig. 2.

Here, wheat farms reflection in the study area will be explored:

Some wheat farms that cultivated in the spring season had different reflection in the first acquisition data-rather autumn wheat farms-but in second acquisition data they had similar reflections i.e., with e

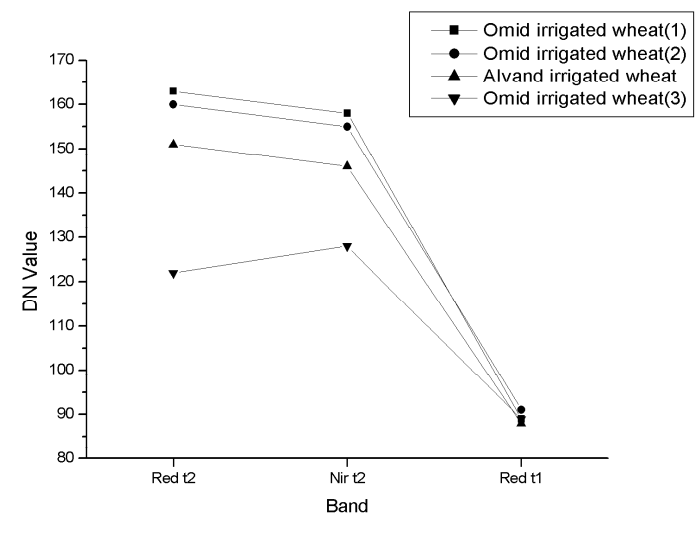

Fig. 4: Reflectance graph between two varieties of nonirrigated wheat

in Table 11 and Fig. 4. Due to different spectral angles, SAM method does not have the potential to classify these two farms in one class. In spite of reflection similarity in the two bands, ML method also doesn't have the potential to classify them in one class by using the samples of $a$ or $b$, due to great reflection difference in one band. this should be done by using training samples from each of the mentioned farms, so that the classification could be done properly. In this classification, if we used a or b as training sample, a and $b$ farms will be classified. The reflection difference between $a$ and $b$ will make no difference in Hue. Spring wheat farms with similar hue to fall what farms can be classified. Consequently, these farms can be classified in one class.

Although, at the first acquisition reflection in irrigated farms, is the same there are some differences in reflection of the second time i.e., a, b, c, f in Table 11 and Fig. 3. But these farms also have similar hues with the potential to be classified in one class, with used one of them as training sample. Due to different spectral angle, SAM method does not have the potential to classify these farms in one class because of different angel. ML method also does not have the potential to classify them in the same class by using samples of a or $b$, because they have different reflection in the two bands. This task should be done by using training samples among each of those farms so that the classification could be done properly. 
Table 12: The overall accuracy (\%) of the three different classifiers for alfalfa

\begin{tabular}{lll}
\hline SAM & ML & IHS \\
\hline 81.9 & 85.3 & 87.1 \\
\hline
\end{tabular}

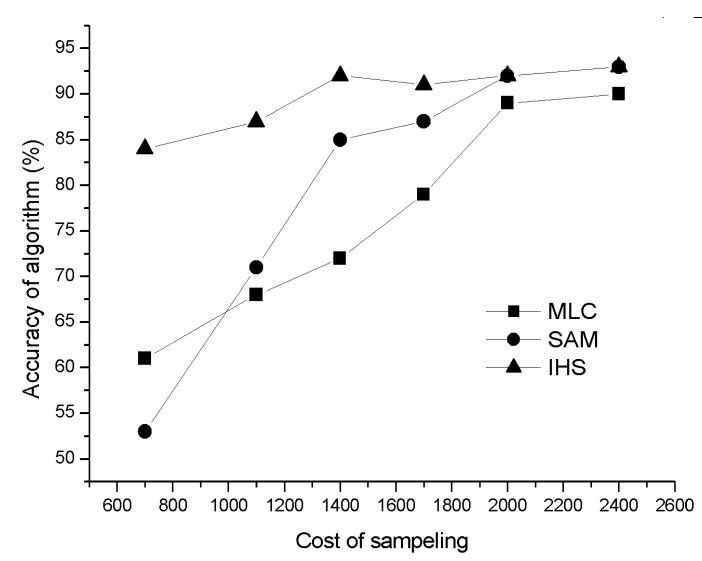

Fig. 5: Chart of sampling cost and classification accuracy

The reflection studies showed that is spite of MC and SAM, IHS has a more potential to recognize changing in reflection and classify these farms with minimum of training samples.

These potentials will lead to increase in efficiency on classification based on IHS. The results of Fig. 2 also confirm this issue.

In addition to classifying wheat farms, alfalfa farms were classified as well based on IHS. The study area for classifying alfalfa was a part with no trees or shrubs-alfalfa with trees in SPOT images have similar cultivating calendar. Alfalfa farms in this area have different growth situation.

These changes in the growth of alfalfa are due to different local condition, availability of water and different irrigation times.

Alfalfa is harvested in different times, so the reflection is different. Regarding these differences, classification of farms is also difficult, in limited samples. The classification was carried out with SAM, ML and IHS algorithms. As Table 12 shows, IHS has the perfect accuracy to recognize and classify alfalfa farms like wheat.

The results of this research showed that when the sampling is done with a great number of samples, the accuracy of ML would be like IHS. But as we know, when the number of samples increases, the expenses also increase. Figure 5, shows the graph of classification accuracy for three algorithms, sampling cost (\$). As graph 5 shows, in all classification algorithms of this research, as the number of samples increases, the expenses increase. But, with respect to its high accuracy IHS, imposes less expense comparing the other algorithms.

On the other hand, in most cases due to time limitation for sampling or due to difficult condition of the area, it is not possible to have lots of samples. But IHS has the potential to present perfect accuracy with limited samples and bands.

\section{CONCLUSION}

Nowadays, extracting the cultivated areas of agricultural products by remote sensing data is preferred and it is developing everyday. Classification of these products seems to face lots of problems. Among them are the reflection changes in the cultivated areas of agricultural products, especially wheat, in satellite images which even make the problem worse. This problem sounds to be more obvious in the areas where agriculture is carried out traditionally or where the conditions for growing are different in a local area and also in areas there is no simultaneous harvest. In most algorithms, in order to classify and extract cultivated area of such products and to reach into high accuracy more training sites must be used with more accuracy. But this high accuracy in classification is followed by a raise in expenses. Hence, in areas where there are not enough samples, the accuracy increase is not possible and consequently the classification can not be carried out truly.

The results of this research showed that IHS algorithm has the ability of recognition and precise classification the wheat farms which have reflection changes. Also IHS algorithm showed that it can classify wheat farms in different areas with similar reflection at a time but different reflection in another time which has been acquired images on those times.

\section{REFERENCES}

1. Alijani, B., 2002. Climatology of Iran. Peyam Noor, Tehran, pp: 62. (In Farsi).

2. Barnett, T.L. and D.R. Thompson, 1982.The use of large-area spectral data in wheat yield estimation. Remote Sensing Environ., 12: 509-518.

3. Bohrani, M.J., 2005. Forege Plants Production. Shiraz University, pp: 150.151. (In Farsi).

4. Chandera, B. and D. Dutta Majumder, 2002. Digital Image Processing and Analysis. Printicle Hall India, pp: 51-52.

5. Dusek, D.A., R.D. Jackson and J.T. Musick, 1985. Winter wheat vegetation indices calculated from combinations of seven spectral bands. Remote Sensing Environ., 18: 255-267. 
6. http://spot5. cnes fr/gb/satellite/satellite.htm.

7. Jahade Keshavarzi Organization, 2005. Hamadan Province.

8. Jensen, J.R., 1986. Introductory Digital Image Processing. Prentice-Hall, New Jersey, pp: 107-135.

9. Labus, M.P., G.A. Nielsen, Lawrence, R.L.R. Engel and D.S. Long, 2002. Wheat yield estimates using multi-temporal NDVI satellite imagery. Int. J. Remote Sensing, 23: 4169-4180.

10. Majnoon Hoseini, N., 2004. Creals of Iran. Jahad Daneshgahi, Tehran, pp: 240. (In Farsi).

11. Murthy, C.S., P.V. Raju and K.V.S. Badrinath, 2003. Classification of wheat crop with multitemporal images: Performance of maximum likelihood and artificial neural networks. Int. J. Remote Sensing, 24: 4169-4180.

12. Noormohamadi, Gh., A. Siarat and A. Kashani, 2004. Grains Agriculture. Shahid Chamran University, Ahvaz, pp: 446. (In Farsi).

13. Khaje Poor, M., 2004. Industirial Plants. Jahad Daneshgahi Publication, Esfahan, pp: 564. (In Farsi).
14. Khoda bande, N., 2003: Grains, Tehran University Publication, pp: 53 (In Farsi).

15. Kruse, F.A., A.B. Lefkoff, J.B. Boardman, K.B. Heidebrecht, A.T. Shapiro, P.J. Barloon and A.F.H. Goetz, 1993. The Spectral Image Processing System (SIPS). Remote Sensing Environ., 44: 145-163.

16. Richards, J.A., 1999. Remote Sensing Digital Image Analysis. Springer-Verlag Berlin, pp: 240.

17. Sepehdost, H., 2003. Application statistic. Noor Elm, Hamadan, pp: 266. (In Farsi).

18. Shahrestani, N., 1998. Tiny grain fruits. Gillan University, Rasht, pp: 150.

19. Schmidt, H. and A. Karnieli, 2000. Remote sensing of the seasonal variability of vegetation in a semiarid environment. J. Arid Environ., 45: 43-60.

20. Swain, P.H. and S.M. Davis, 1978. Remote Sensing: The Quantitative Approach. McGraw Hill Book Company. New York, pp: 397-399.

21. Vissers, M.A.M. and D.H. Hoekman, 2003. A new polarimetric classification approach evaluated for agricultural crops. Geosci. Remote Sensing, 41: 2881-2889. 